\title{
Evolutive assessment of endothelial function in metabolic control and microvascular complications in type 1 diabetes mellitus patients
}

\author{
Winston Boff, Antonio Marcos Vargas da Silva, Marcia Puñales*, Gislaine Vissoky Cé, Marcello Casaccia Bertoluci \\ From 20th Brazilian Diabetes Society Congress \\ Porto Alegre, Brazil. 11-18 November 2015
}

\section{Background}

Long-term type 1 diabetes (T1D) is associated to microvascular complications. In a previous study of our group, we observed that endothelial dysfunction (ED) was present in half of adolescents under 5 yrs. of T1D duration, even before the onset of microvascular disease. Although ED is associated to vascular complications, the natural history and risk of developing these complications is not yet understood.

\section{Objective}

The aim of the study was to determine the potential evolution of ED overtime and if its determination could be predictive for albuminuria in T1D patients.

\section{Materials and methods}

Observational cohort study with 7 yrs. of follow up, including $40 \mathrm{~T} 1 \mathrm{D}$ patients, mean age of $22.6 \pm 4.2 \mathrm{yrs}$. The assessment of endothelial function and vascular stiffness was performed respectively through flowmediated dilation (FMD\%) in brachial artery and dilation mediated by nitroglycerin (NTG\%). ED was defined by $\%$ of dilation inferior to $8 \%$. HbA1c was measured at 3 months intervals over 7 yrs. Data were analyzed comparatively between 2007 and 2014 for\%ED (2007: ED1 and 2014: ED2) and\%NTG (NTG1 and NTG2), using ttest for dependent samples and McNemar paired test to comparison.

\section{Results}

Data were available of 40 T1D patients, mean follow up of 7 yrs. Mean and SD for ED and NTG were

\footnotetext{
* Correspondence: mpunales@aeromundi.com.br

Hospital da Criança Conceiçao e Instituto da Criança Com Diabetes-GHC,
} Porto Alegre, Brazil

respectively: ED1: $9.6 \pm 6.8$ vs ED2: $6.9 \pm 4.9 \%, \mathrm{p}=0.0032$ and NTG1: $22.9 \pm 9.8$ vs NTG2: $16.8 \pm 4.5 \%, \mathrm{p}=0.000$. Of had ED in 2007, 27.5\% remained in ED in 2014 while 17.5\% ED patients in 2007 reverted to normal in 2014. total of $45 \%$ of the patients had ED in 2014, being out ED in 2014 was respectively: $8.8 \pm 1.7$ and $8.6 \pm 1.7 \%$ (0.646). Interestingly, $47.5 \%$ patients improved ED to normality, despite a slight increase in $\mathrm{HbA} 1 \mathrm{c}$ of $.9 \%$. The presence of albuminuria was not assorespectively $(\mathrm{p}=0.784)$ and $29.6 \pm 63 \mathrm{vs} 26.2 \pm 55 \mathrm{mg} / \mathrm{dL}$ in

\section{Conclusion}

The resuts showed that in most T1D both ED and vascuduration is the main predictor of deterioration of ED, independently $\mathrm{HbA1c}$ or albumiruria. Longer studies are future atherosclerosis in T1D.

Published: 11 November 2015 